\title{
$\mathbb{K}$ ajian Analitik
}

\section{KEBUDAYAAN, PENDIDIKAN, DAN PEMBERDAYAAN SUMBERDAYA MANUSIA INDONESIA}

\author{
Prof. Dr. Ir. H. Darwis Suharman Gani, M.A
}

\section{Pendahuluan}

Pengembangan sumberdaya manusia terkait dengan banyak aspek kehidupan manusia dan bangsa serta kebudayaannya. Indonesia yang multietnik dan multibudaya dengan lebih kurang 216,42 juta penduduk dengan angkatan kerja sebesar 100,32 juta pada tahun 2004 (International Institue for Management Development - IMD, 2005), merupakan negara berpenduduk keempat di dunia dan salah satu negara terpadat penduduknya. Menurut Suwarsih Warnaen (2002), lebih dari 200 etnik tersebar di pulaupulau di Indonesia, dengan sebaran tak merata dan kebudayaan yang beragam, kebudayaan yang mempengaruhi proses pendidikan, mempengaruhi pelaksanaan pemberdayaan sumberdaya manusia dan pada akhirnya mempengaruhi pengembangan sumberdaya manusia Indonesia secara utuh.

Mutu manusia Indonesia berada di urutan ke 117 dari 175 negara di dunia, berada di bawah Viet Nam di urutan ke 110, dengan pendapatan per kapita US\$810 - pada tahun 1997 US\$3.038. Mutu pendidikan, menurut International Aducational Achievement - IEA, kemampuan membaca siswa Sekolah Dasar (SD) berada di urutan ke 38 dari 39 negera dan menurut the Third Mathematics and Science Study - TIMSS kemampuan matematika siswa SMP di Indonesia di urutan 34 dari 38 negara, sedangkan kemampuan IPA di urutan 32 dari 38 negara. Masalah persaingan competitiveness dalam bidang ekonomi peringkat daya saing global tahun 2004 di peringkat ke 58 dari 60 negara dan tahun 2005 turun menjadi nomor 59 dengan aspek infrastruktur terburuk dari 60 negara. Bagaimana mendidik sumberdaya manusia dengan begitu banyak masalah mendasar bagi kehidupan yang jauh dari harapan masyarakat, bangsa dan negara Indonesia.

Mendidik adalah memanusiakan manusia dan terkait dengan harga diri dan harkat hidup manusia. Dengan banyak usaha telah dilakukan, di antaranya perbaikan kurikulum, penggantian undang-undang, deregulasi pendidikan, dan peningkatan anggaran pendidikan belumlah cukup untuk meningkatkan mutu lulusan dan meningkatkan mutu sumberdaya manusia Indonesia berpendidikan.

\section{$\underline{\text { Pemberdayaan }}$}

Mutu sumberdaya manusia merupakan masalah bagi pemerintah bersama-sama masyarakat, karena mutulah yang menentukan peningkatan partisipasi masyarakat dalam proses pemberdayaan sumberdaya manusia, masyarakat, birokrasi dan organisasi. Akulturisasi masyarakat Indonesia merupakan proses pengembangan dan pemberdayaan sumberdaya manusia Indonesia dapat tercapai bila kebijakan dilaksanakan dengan perhatian khusus kepada rencana dan strategi yang tepat dengan memperhatikan kaum miskin, petani, pekerja, wanita dan demokrasi. Manajemen ilmiah merupakan filosofi untuk mengatur dan mengendalikan birokrasi yang sangat besar pada tahun 1920-an dan 1930-an, maka 
pemberdayaan merupakan filosofi untuk menjalankan organisasi pada abad ke XXI.

Banyak organisasi akan menghadapi transformasi demikian cepat, mengubah gaya dan cara mereka sebagai tanggapan terhadap lingkungan yang berubah. Persaingan akan sangat kuat dalam lingkungan baru yang terpengaruh oleh teknologi dan informasi serta kecepatan dan ketepatan waktu, baik di dalam maupun di luar negeri. Pemberdayaan merupakan:

- upaya peningkatan harkat dan pribadi sumberdaya manusia seutuhnya, dengan upaya mendorong, memotivasi, meningkatkan kesadaran akan potensinya, menciptakan iklim kerja untuk berkembang, memperkuat daya, potensi yang dimiliki dengan langkah positif mengembangkannya, penyediaan pelbagai masukan, dan membuka akses ke peluang opportunities, peningkatan taraf pendidikan, kesehatan, akses terhadap modal, teknologi tepat guna, informasi, lapangan kerja dan pasar dengan kelengkapan sarana dan prasarana.

Pemberdayaan bukan hanya untuk sumberdaya manusia, akan tetapi juga terhadap pranata, sistem dan struktur, pembaruan kelembagaan, penanaman nilainilai, peran masyarakat di dalam organisasi, khususnya dalam pengambilan keputusan dan perencanaan, sekaligus merupakan pembudayaan demokrasi, pembelaan yang lemah terhadap yang kuat dan menanggulangi persaingan. Dengan pemberdayaan dihasilkan sumberdaya manusia yang tidak tergantung kepada pemberian, semakin mandiri dan bertumbuhnya harga diri.

\section{Pengembangan Konsep Pemberdayaan}

Pada tahun 1950-an, dimulai oleh para teoritikus motivasi di Amerika Serikat, dimulai dari teori motivasi yang didasarkan atas kerja - work-based theory of motivation (Foy, 1994 dan Lowe, 1995), dengan inti dari teori tersebut adalah bahwa manusia akan bekerja lebih giat bila diperlakukan sebagai manusia - human beings, dari penyebab paksaan dan ketakutan akan hukuman.

Model peranserta prapemberdayaan preempowerment models of participation, terdiri dari:

1) Pendekatan teori bidang -field theory approach, bila diizinkan untuk berperanserta dalam pengambilan keputusan organiasi, motivasi dan produksi mereka meningkat .

2) Kerja pada the Taristock Institute di Inggris mengarah pada teori sistem sosioteknik - socio-technical system theory, metoda pengujian prasyarat teknis dan manusia dari kerja, secara erat;

3) Douglas McGregor pada tahun 1960-an dengan Teori $\mathrm{Z}$ dan Teori $\mathrm{Y}$;

4) Frederich Herzberg, manusia secara individual dimotivasi oleh prestasi, pengakuan, tanggungjawab, beban kerja dan kesempatan untuk maju -job enrichment;

Pemberdayaan adalah konsep yang lahir sebagai bagian dari perkembangan alam pikiran masyarakat dan kebudayaan, khususnya Masyarakat Barat yang tampak pada tahun 1970-an sebagai gerakan antikemapanan, anti-sistem, anti-struktur dan antideterminisme yang diterapkan dunia kekuasaaan, dan sekarang dikenal sebagai gerakan Aufklarung atau Enlightment, Muara determinisme adalah sistem keagamaan sebagai basis ideal dan organisasi gereja dan monarki sebagai basis struktural. Otoritas keagamaan dan kerajaan tidak lagi mendapat tempat pada masyarakat, selain disebabkan oleh perkembangan ilmu, pengetahuan, sistem informasi dan teknologi, juga kebebasan rasio dan individu turut mempercepat proses pemberdayaan. Sistem alternatif yang timbul menggantikan sistem keagamaan dan kerajaan yang deterministik, meliputi liberalisme, individualisme dan rasionalisme. Mencari sistem alternatif untuk menggantikan kekuasaan keagamaan dan kerajaan, disebut sebagai penghapusan kekuasaan - 
depowerment, dan karenanya diperlukan pemberdayaan - empowerment, yang merupakan kegiatan emansipasi dan liberalisasi manusia serta penataan segala kekuasaan dan penguasaan yang menjadi inti dan dasar - substansi - substance, dari konsep pemberdayaan.

Tahapan pemberdayaan menurut Wilson (1996) terdapat 3 (tiga) tahapan,yaitu:

\section{1) Tahapan Politik}

Pemberdayaan secara perlahan melekat sebagai mekanisme bantuan diri untuk manusia lain - mechanism of self-help for people. Ketergantungan pada orang lain secara perlahan diganti dengan ketergantungan pada diri sendiri secara nasional, dalam sistem ekonomi, pendidikan, kebudayaan, efisiensi dan efektivitas, sumberdaya dan persaingan.

\section{2) Tahapan Organisasi}

Konsep modern yang mendorong organisasi, seperti total quality management, habitual improvement, performance management, self-directed team work, internal customers, competence management etc. Banyak faktor pemberdayaan dan ketidakberdayaan tergantung pada nilai-nilai, perilaku, sistem, prosedur dan budaya organisasi.

\section{3) Tahapan Sumberdaya Manusia Individual}

Pada tingkat atau tahapan individual, perubahan dari sumberdaya manusia yang sebelumnya kurang percaya diri selalu penurut dan patuh serta dikendalikan oleh kekuasaan, keterampilan, status dan bayangan pribadi, meningkat kepada hal-hal dan imbalan yang lebih besar. Proses pemberdayaan berbeda untuk setiap sumberdaya manusia, baik yang memerlukan waktu singkat, maupun waktu yang lama, menjadikan perubahan hidup dan perilaku mereka untuk mencapai tujuan yang semula dianggap tidak mungkin.

\section{Batasan Pemberdayaaan}

The Webster \& Oxford English Dictionary memberikan batasan untuk pemberdayaan sebagai:

1) To give power or authority to Memberi kekuasaan, mengalihkan kekuatan atau mendelegasikan otoritas wewenang ke pihak lain ; dan

2) To give ability to or to enable - Upaya untuk memberikan kemampuan atau keberdayaan.

Foy (1995) membedakan antara empowerment dan delegation dengan contoh : "You give your daughter money to buy a pair of jeans that's delegation. If you give her a clothes allowance she can spend as she chooses, that's empowerment".

Pemberdayaan memiliki segi positif "merasa ikut memiliki - rumongso melu hardarbeni", berperanserta dalam budaya organisasi, dan tujuan yang ditetapkan bersama. Covey (1992) berpendapat bahwa pemberdayaan, adalah "management's job is empowerment, and empowerment basically means - Give a man a fish and you feed him for a day. Teach him how to fish and you feed him for a life time". Seperti dikatakan oleh Wilson (1996): "Empowerment is a management initiated process which captures the imagination and desires of all the people in the organization thereby enabling them to develop and utilize all their talents and abilities in the achievement of the organizational goals and their job and career goals".

Lowe (1995) dalam Nyoman Sumaryadi (2005) secara spesifik memaparkan beberapa keuntungan - benefits yang didapatkan oleh organisasi bila melakukan proses pemberdayaan individu dengan 3 (tiga) keuntungan, yaitu:

1. Kepekaan terhadap pasar, dengan peningkatan perhatian kepada masyarakat, fleksibilitas yang semakin besar, meningkatnya motivasi dan kemampuan lebih baik dalam menghadapi perubahan;

2. Pemberdayaan memberikan dampak 
terhadap individu sumberdaya manusia yang diwujudkan dalam peningkatan motivasi, komitmen, energi dan antusiasme, tingkat keterampilan yang lebih tinggi, meningkatnya kinerja individu;

3. Pemberdayaan mempengaruhi sistem dan strukktur serta konfigurasi organisasi, dengan berkurangnya penggantian staf reduced staff turnover, meningkatnya kontribusi finansial dan semakin rendahnya biaya administrasi.

\section{$\underline{\text { Kebudayaan }}$}

Pembudayaan sumberdaya manusia secara individual, dalam kelompok, dalam organisasi dan masyarakat, mendasari terbinanya budaya organisasi atau budaya perusahaan - corporate culture. Ilmu Kebudayaan - Culturology merupakan cabang ilmu pengetahuan kemasyarakatan - sosial sciences, yang mempelajari hal ihwal kebudayaan sebagai gejala mandiri manusia dan dikembangkan oleh L.A. White sebagai the Science of Culture. Indonesia dengan multikultur - multiculture dan multietnik multiethnic, dengan kondisi geografik yang menantang sumberdaya manusia untuk bekerja lebih keras dalam organisasi-organisasi yang siap bersaing di era globalisasi, abad ke XXI yang ditentukan oleh ilmu dan pengetahuan berpola teknologi dan informasi. Budaya multikultur dengan beragam tahapan peradaban - civilization dan kebudayaan - culture, memberikan keuntungan tersendiri untuk menunjang pembinaan budaya organisasi yang berkesinambungan.

Kebudayaan diartikan oleh A.L. Kroeber dan Clyde Kluckhohn (1952), sebagai berikut: "Kebudayaan terdiri atas pola secara nyata ataupun tersirat dari dan untuk perilaku yang diperoleh dan diteruskan dengan lambang-lambang yang membentuk hasil karya yang unik dari kelompok manusia; inti dari kebudayaan terdiri dari gagasan tradisional dan nilai-nilai yang menyertainya".

\section{Budaya Indonesia}

Ciri-ciri budaya Indonesia

(Kuntjoroningrat, 1985):

1) Nilai budaya tidak berorientasi pada karya manusia - non achievement oriented;

2) Orientasi budaya terlalu banyak terarah pada masa lampau, sehingga melemahkan seseorang untuk melihat ke masa depan;

3) Cenderung membuat seseorang melarikan diri ke dunia kebatinan yang tak sesuai dengan jiwa rasionalisme;

4) Membuat seseorang cenderung untuk menggantungkan diri kepada nasib;

5) Cenderung menilai tinggi konsep sama rasa yang mewajibkan sikap konformisme dan tidak mendorong kemajuan, dan

6) Adat sopan santun yang berorientasi ke atas, yang dapat mematikan keinginan berdiri sendiri dan berusaha sendiri.

Akibat perjuangan kemerdekaan, budaya Indonesia memiliki ciri-ciri tambahan sebagai berikut:

1) Mentalitas meremehkan mutu;

2) Mentalitas yang suka "potong kompas" - menerabas;

3) Sifat tidak percaya diri;

4) Sifat tidak berdisiplin murni; dan

5) Mentalitas suka mengabaikan tanggung jawab.

Budaya Indonesia tidak sejalan, bahkan berlawanan dengan beberapa ciri dari sikap dan nilai yang sesuai dengan kehidupan modern, yaitu:

1. Terbuka terhadap inovasi dan perubahan;

2. Menumbuhkan perhatian pada masalah di luar diri sendiri dan dengan demikian akan menumbuhkan sikap yang lebih demokratis.

3. Lebih berkonsentrasi pada masa depan daripada masa lampau;

4. Menghargai perencanaan dan menjalankan kehidupan berdasar rencana yang dibuat;

5. Menggunakan potensi lingkungan secara aktif dan tepat sehingga menjamin pembangunan berkelanjutan yang berwawasan lingkungan;

6. Mengandalkan perhitungan, sehingga tidak tergantung pada nasib - destiny; 
7. Menghargai martabat manusia - menjamin hak azasi manusia dan keadilan;

8. Dapat melibat kegunaan ilmu dan teknologi; dan

9. Menghargai pekerjaan sesuai prestasi.

\section{Budaya Organisasi}

Budaya organissi menurut Jay Heyzer and Barry Render (2004), adalah:

"One of the great challenges as operations go global is reconciling differences in social and cultural behavior. With issues ranging from bribery, to child labor, to the environment, managers sometimes do not know how to respond when operating in a different culture. What one country's culture deems acceptable may be considered unacceptable or illegal in another".

Menurut Charles Handy (1994), terdapat 4 (empat) jenis budaya organisasi, yaitu:

1. Budaya organisasi Kekuasaan - ZEUS;

2. Budaya organisasi Peran - Apollo;

3. Budaya organisasi Tugas - Athena, dan

4. Budaya organisasi Individu - Dioysius.

Wilson (1996) menyatakan bahwa budaya organisasi penting bagi pemberdayaan sumberdaya manusia karena proses pemberdayaan sering menuntut pemutusan dari tradisi dan perubahan dalam budaya. Bila budaya organisasi memberikan kestabilan dan kesamaan yang dapat menjadi budaya yang menguntungkan, serta karena ia didasarkan pada masa lalu, budaya organisasi dapat bertindak sebagai rem terhadap pemikiran dan gagasan baru. Ini tidak hanya merupakan hambatan bagi pemberdayaan, akan tetapi juga pada pemikiran, perasaan dan sikap masyarakat.. Karena unsur-unsur budaya yang tidak terlihat - the cultural invisibility yang berakar pada masa silam, terdapat pula kesenjangan budaya - cultural lag di mana organisasi sudah terjerat dan tertanam dalam nilai-nilai, pemikiran, aplikasi dan perilaku yang tertinggal zaman. Dalam proses pemberdayaan, organisasi akan selalu berhadapan dengan kedua masalah di atas.
Proses pemberdayaan menuntut adanya perubahan budaya - cultural change

\section{$\underline{\text { Pendidikan }}$}

Menurut Sudarwan Danim (2003), pendidikan pada intinya merupakan proses penyiapan subyek didik menuju manusia yang bertanggung jawab. Dijelaskan pula bahwa pendidikan adalah:

1) Proses kemanusiaan dan pemanusiaan secara simultan;

2) Proses sosial yang dibangun untuk menggali dan mengembangkan potensi dasar manusia untuk menjadi insan beradab;

3) Proses interaksi manusiawi yang dilakukan oleh subyek dewasa untuk menumbuhkan kedewasaan pepada subyek yang belum dewasa dengan menggunakan potensi yang ada dan sesuai;

Kegiatan pendidikan mencakup produksi dan distribusi pengetahuan yang terjadi, baik dalam skema/struktur kelembagaan maupun pada proses sosial pada umumnya. Ilmu pendidikan terdiri dari dua ranah - domain, yaitu ilmu pendidikan teoritis dan ilmu pendidikan praktis. Obyek studi ilmu pendidikan adalah berbagai aspek interaksi pesikologi, sosial, budaya antara peserta didik dan pendidik. Dalam hal ini, peserta didik merupakan subyek dengan segala karakteristik pribadi, kebutuhan, aspirasi, serta nilai-nilai yang dianut. Dalam konteks pengembangan teori-teori pada tiap komponen kurikulum, belajar, mengajar, lingkungan dalam arti luas dan untuk bidang-bidang yang bersangkutan, diperlukan teori-teori ilmu lain, misalnya: filsafat, psikologi, sosiologi, antropologi, administrasi, ekonomi, politik dan kebudayaan.

Pendidikan dasar dan menengah di Indonesia beberapa kali memiliki konsep pendidikan, di antaranya Konsep Pendidikan Link and Match, Life Skill dan Kurikulum Berdasar Kompetensi (KBK) atau dikenal dengan Kurikulum 2004. Mengenai Kurikulum 2004, basis atau dasar kompetensi, didasarkan pada anggapan bahwa seseorang dianggap kompeten bila: 
1) Memiliki landasan kemampuan pengembangan kepribadian;

2) Kemampauan penguasaan ilmu dan keterampilan - know how dan know why;

3) Kemampuan berkarya - know to do;

4) Kemampuan menyikapi dan berperilaku dalam berkarya sehingga dapat mandiri, menilai dan mengambil keputusan secara bertanggung jawab; dan

5) Dapat hidup bermasyarakat dengan bekerja sama, saling menghormati dan menghargai nila-nilai pluralisme, dan menghargai kedamaian. - to live together.

Pendekatan konsep Kurikulum 2004, akan mendasari perkembangan kurikulum pendidikan pra sekolah, dasar, menengah, tinggi, formal maupun nonformal ataupun informal. Kurikulum 2004 berdasarkan konsep pendidikan untuk semua dan pendidikan sepanjang hayat - education for all and - life long education seperti diamanatkan oleh Perserikatan Bangsa-Bangsa.

\section{Konferensi UNESCO}

1998 mencanangkan 4 (empat) pilar pendidikan:

1) Learning to know - peserta didik perlu mengetahui landasan ilmu dan pengetahuan yang terus berkembang pesat;

2) Learning to do - mengenal dan memahami ilmu dan pengetahuan akan tetapi juga mengaplikasikannya; menganalisis, mengaitkan dan mengambil kesimpulan serta mengevaluasinya. Learning to know dan Learning to do lebih menekankan pada keterampilan hidup - Life skill;

3) Learning to be - menekankan pada penggalian potensi diri peserta didik tidak hanya pada life skill yang diminatinya, akan tetapi juga pengembangan potensi kepribadiannya untuk membentuk eksistensinya sebagai manusia intelektual intellectual human beings yang memiliki semangat profesionalisme, kepemimpinan dan kepribadian positif.

4) Learning to live together - harus belajar hidup bersama di lingkungannya sebagai makhluk sosial, juga bekerja dalam team work saling membantu dan peduli pada sesama. Pilar ketiga dan keempat lebih menekankan bagaimana menjadi manusia seutuhnya, tidak saja dalam intelektualnya akan tetapi juga moral dan kepribadiannya.

$\begin{array}{llll}\text { Setelah } & \text { dipakai } & \text { sebagai } & \text { dasar } \\ \text { Kurikulum } & 2004 & \text { yang } & \text { sedang }\end{array}$
diimplementasikan, wajar bila terdapat banyak pendekatan yang berbeda, akan tetapi dasar kebudayaan bangsa yang merupakan aspek utama kehidupan suatu bangsa.dan proses pendidikan tidak dapat dipisahkan dari pembinaan dan pemberdayaan sumberdaya manusia Indonesia.

\section{Diskusi}

Indonesia sebagai negara yang multietnik dan multibudaya bahkan disebut juga sebagai supraetnik dan suprakultur, bagi banyak ilmuwan merupakan tantangan yang segera perlu dijawab. Manusia yang demikian besar jumlah angkatan kerjanya di dunia, dapat merupakan masalah sosial dan ekonomi yang dapat berimbas kepada negara-negara lainnya. Ketertinggalan kita dan ketidak konsistenan kita pada kemajuan ilmu, teknologi dan informasi membawa negara dan bangsa Indonesia seakan bergelombang dalam eksistensi di percaturan kehidupan bangsabangsa di dunia, betapa di antaranya dalam bidang politik bertahun lalu kita menonjol dan berperan aktif, dalam olahraga kita sejajar negara maju, dalam ekonomi pernah diramal akan menjadi salah satu macan Asia, di bidang pendidikan kita berjasa memberikan apa yang kita miliki uintuk mencerdaskan bangsa lain, dalam bidang pertahanan pengalaman sebagai pasukan internasional dipuji mutunya, dan dalam bahasa kita mempelopori bagaimana menyatukan bangsa yang demikian beragam menjadi bangsa yang satu. Mengapa demikian? Kebudayaan Indonesia tidak mendukung, disebabkan oleh demikian ragam budaya dan kebudayaan kita, kita tidak pernah bersatu dalam seni, budaya, perilaku, sikap, filsafat hidup, cara berfikir, sistem pengambilan keputusan, kepribadian, disiplin, nilai-nilai, norma, pola pikir, gaya hidup, dan budi pekerti.

Tidaklah mudah menjadi bangsa yang gemah ripah loh jinawi, akan tetapi lebih sukar bila kita malahan tidak berkeinginan 
untuk meniti jembatan penderitaan menjadi manusia yang terombang-ambing antara kebudayaan, ketidakpastian sistem pendidikan dan pola pemberdayaan dalam mengembangkan sumberdaya manusia yang bermutu. Pemberdayaan memerlukan keberanian untuk melihat kenyataan, khususnya kemampuan dan kompetensi yang dimiliki bangsa sekarang ini, bukan menjadikan Indonesia masa lalu sebagai yang terbaik dan dipuja-puji.

Kebudayaan bukanlah dalam arti sempit seni dan budaya, akan tetapi mencakup masalah filsafat bangsa, gaya hidup, tata kehidupan, cara berfikir, pembinaan sikap, mental, moral dan budi pekerti yang saharusnya dibina sejak di rumah tangga, pra sekolah dan Taman Kanakkanak. Sikap inovatif, kreatif, inisiatif dan keberanian menghadapi manusia lainnya dipupuk sejak dini melalui pendidikan informal, nonformal dan formal. Ketersinggungan masalah kebendaan/duniawi dengan masalah ukhrowi hendaknya dihadapi dengan keberanian melihat kenyataan, sebab dalam implementasi Kurikulum 2004 sedikitnya terdapat 9 (sembilan) kompetensi yang perlu dikembangkan, yaitu kompetensi:

1) Dasar iman dan taqwa;

2) Dasar bahasa Arab dan Inggris;

3) Dasar komputer dan internet;

4) Tata krama dan budi pekerti;

5) Dasar komunikasi dan teknologi;

6) Dasar penelitian;

7) Dasar organisasi;

8) Dasar kemasyarakatan dan

9) Dasar kewirausahaan.

\section{$\underline{\text { Kesimpulan }}$}

Mengembangkan suberdaya manusia Indonesia melalui pemberdayaan manusia Indonesia, harus berdasarkan kebudayaan Indonesia, jauh dari pandangan sempit kebangsaan - chauvinism, haruslah ditegakkan dalam setiap kegiatan pendidikan dan pemberdayaan. Karenanya tindakan berikut perlu dilakukan:

1. Perlu dibentuk Departemen Kebudayaan Republik Indonesia;

2. Perlu badan strategik pendidikan yang berakar, berdasar budaya dan kebudayaan Indonesia, dengan memanfaatkan segmen pendidikan dan peran serta ahli-ahli pendidikan, terutama dari Indonesia, dalam satu badan tingkat nasional langsung di bawah Presiden Republik Indonesia;

3. Perlu diusahakan strategi pemberdayaan sumberdaya manusia Indonesia, dengan strategi yang berkesinambungan, dengan visi dan misi yang jelas dan melibatkan seluruh aspek bangsa dan negara Indonesia;

4. Perlu usaha keras untuk menyadari betapa pentingnya kebudayaan bagi suatu bangsa dengan bantuan informasi terarah dan khas Indonesia;

5. Perlu kerjasama dengan masyarakat dunia untuk bahu membahu membentuk dunia yang adil untuk semua bangsa.

\section{$\underline{\text { Rujukan }}$}

I Nyoman Sumaryadi. 2005. Perencanaan Pembangunan Daerah Otonom \& Pemberdayaan Masyarakat. Jakarta: Citra Utama.

Kuntjaraningrat. 2002. Manusia dan Kebudayaan di Indonesia. Jakarta: Jembatan.

Maurits Simatupang. 2002. Budaya Indonesia yang Supraetnis. Jakarta: P. S. Sinanti.

Prijono T. dan S. Soemitro. 19980. Pemberdayaan Penduduk dan Peningkatan Kualitas Sumberdaya Manusia. Jakarta: Cita Putra Bangsa.

Sudarwan Danim. 2003. Ekonomi Sumberdaya Manusia. Bandung: Pustaka Setia.

Suwarsih Warnaen. 2002. Stereotip Etnis dalam Masyarakat Multietnis. Jakarta: Mata Bangsa. 